\title{
What makes a 'good' review article? Some reflections and recommendations
}

\section{Martin S. Hagger}

\section{School of Psychology and Speech Pathology, Curtin University, Perth, Western Australia}

Looking back on the hundreds of articles I read during the course of my doctoral research, a few have left a lasting and indelible impression on me and still influence my thinking to this day. Some of these articles fall into the 'classic' experiment or study category and represent groundbreaking research that changed the way psychologists viewed and theorised on a particular behavioural phenomenon or adopted a unique methodological approach that paved the way for future research. Others were narrative or systematic reviews of a particular field or area, but were equally as influential on my, and certainly many others', thinking and were highly influential in advancing knowledge in the area and catalysed future research. Reflecting on these highlyinfluential review articles led me to further ruminate on the key ingredients that make a 'good' review article; a highly pertinent question for the editor of a review journal such as Health Psychology Review which has ambitions to be the lead forum for reviews on health psychology and behavioural medicine! Perusing the characteristics and features of the reviews that made such an impression on me, and likely many others, I have drawn up the following shortlist of candidate features that make a 'good' review article and present them here:

(1) Originality

(2) Advances knowledge and original thinking

(3) Theory-based

(4) Evidence-based

(5) Accurate, comprehensive and rigorous

(6) Recommendations for future enquiry

(7) Stimulates debate

I will touch upon each of these features in turn and how they pertain to the articles published in a journal like Health Psychology Review (HPR) in the hope that this will help guide those considering authoring a review in the field and submitting to the journal. I reference recently published reviews from HPR which are excellent examples of the features I propose and I strongly encourage prospective authors to read these articles paying attention to the features that make them 'good' reviews.

Originality. It will come as no surprise to readers of the journal that the reviews published in HPR have been accepted because they are judged to make a unique contribution to the literature. By this, I do not mean that a review should, necessarily, report the creation or development of a new theory, model, or way of thinking, but it should report on a new and innovative way of viewing a particular field or phenomenon in health psychology of behavioural medicine or offer unique insight into a particular relationship or effect observed in the field. Some review manuscripts submitted to HPR for consideration for publication are expertly executed and very well designed, but, alas, do not offer anything new. Such submissions, consequently, fall at the first hurdle. A good review must be informative about the field and focus on a topic in a way that has not been done before. All reviews published in HPR fulfil this criterion, but good illustrations are DeFrank and Brewer's proposed model of false-positives for mammography (2010), Sweeny and Cavanaugh's (2011) model on 
uncertainty and responses to health news, DiMatteo, Haskard-Zolnierek, Martin's (2011) metaanalytically derived three-factor model of patient practice, and Hall and Fong's (2010) rejoinder on their temporal self-regulation theory and associated commentaries (Borland, 2010; Cameron, 2010; Sallis, 2010; Webb \& Sheeran, 2010). In contrast, descriptive reviews of a particular field may have some value in terms of summarising the state-of-the-literature, but its impact will be limited as it offers no new perspective on the field.

Advances Thinking and Knowledge. Closely related to originality, a 'good' review will also challenge previous ideas and contribute to understanding of certain topics, areas, or ideas. Again, this means that review articles need to go beyond mere description and 'state-of-the-literature' summaries and develop new ideas and ways of thinking. While reviews should be evidence-based and well designed, they should also offer new insight into understanding the topic through innovative thinking that logically emerges from the evidence and, in all likelihood, extends it beyond current knowledge. Although it may not appear so on the surface, this ideal applies to all review types, including meta-analyses and systematic reviews. The latter, although empirical, should not only seek to synthesise the literature but also demonstrate how the synthesis can help further understanding of health behaviour and other salient outcomes in the field (e.g., Annesi, Marti, \& Stice, 2010; Dodd \& Forshaw, 2010; Floyd \& Moyer, 2010). In summary, no reader should feel it necessary to raise the 'so what' question after reading a review article, narrative or empirical, published in HPR.

Theory based. HPR reviews should to be based on theory. Reviews published in HPR are an excellent platform on which to develop ideas and propose new ways of thinking about phenomena in psychology. Review articles, therefore, need to take into consideration what has gone before, as well as current thinking, and use these, along with evidence, as a basis to develop new ideas. In addition, psychology is a very 'theory rich' discipline and, if anything, there are probably too many different approaches to understanding phenomena in psychology applied to health and illness. This can lead to confusion and bewilderment, especially from the perspective of early-career researchers and students who seek to develop a basic understanding of health behaviour and behavioural phenomena about health and illness. HPR reviews can assist in this regard by helping to integrate the plethora of theories present in the discipline toward eliminating redundancies (e.g., constructs with similar content but different terms) and increase complementarity (e.g., demonstrate that one theory can help address the shortcomings of another) (Hagger, 2009, 2010).

Evidence based. New theories cannot be 'plucked from thin air' and the author of a review cannot advance and extend knowledge on a whim. Authors need to pay due diligence by taking previous research findings into consideration when developing new ideas. Just as a researcher needs to use previous investigations as a basis for his or her latest empirical study, so the author of a review article needs to consider previous evidence regarding the psychological phenomenon under scrutiny and use this as a basis for forming new ideas and theories regarding that phenomenon (for an excellent example of an evidence-based theoretical review see Morton et al., 2010).

Accurate, comprehensive, and rigorous. Review article authors need to adhere to the highest methodological standards when it comes to the conduct of the review process and the reporting of previous research, both of which are key considerations when review article manuscripts are reviewed by referees in HPR. Many times have reviews been rejected from the journal because an 
author has neglected important studies without appropriate justification which severely limits the validity and impact of the research. In such cases, authors need to ensure that no stones have been left unturned when it comes to encompassing previous research. The methods also need to be highly-appropriate and tailored to the type of review and phenomenon under scrutiny. Authors of reviews need to make sure that they adopt an appropriate and systematic approach to their review, such as the selection of analytic method in the case of quantitative and systematic reviews (e.g.Dodd \& Forshaw, 2010; Floyd \& Moyer, 2010), the need for selecting the optimal search strategy and studies to be included when it comes to narrative reviews (e.g., Gilliam \& Schwebel, 2011; Perez \& Cruess, 2011), and the identification of appropriate phenomena and narrative sources in qualitative research (e.g.,Lyons, 2011; Soundy et al., 2011; Stephens, 2011). Finally, review authors need to ensure that they communicate their ideas using the appropriate scientific discourse and do so in an efficient and lucid manner. Far too often the HPR editorial team receives reviews that are encumbered by overdescription and lax language which only serves to frustrate the reader who is often looking for a pithy overview of the salient 'headline' findings, an associated evidence-based take-home message, and, most importantly, what gaps exist in knowledge.

Recommendations for further research. An important aspect of advancing thinking and knowledge on a particular topic is to foster future research enquiry and stimulate further empirical work. This is should be a key aspect of the studies published in HPR; we consider recommendations for future research an essential aspect of the process by which reviews develop thinking. Review articles should therefore be diligent in generating new questions that need to be addressed through future empirical research and serve to drive the field forward by posing the questions and hypotheses that need to be targets of new studies. Excellent examples abound in HPR, but for a particularly cogent example of the provision of future research directions arising from a review of the extant research, I point readers in the direction of van't Riet and Ruiter's (2011) article on defensive reactions to health-promoting information.

Stimulating debate. Review articles should not only serve as a catalyst for future research endeavours, they should also stimulate future debate among theorists and researchers on the key questions relating to theory, research, and practice in health psychology. HPR as well as many other review journals recognise the value of scholarly debate about salient issues and contemporary thinking about particular theories and processes in the field. Theorists and researchers frequently hold differing, or even diametrically opposed, views on particular issues and reviews can be an important source for the airing, discussion, refuting and reconciliation of these viewpoints. This is why it has been part of the editorial team's mission to further stimulate debate in HPR and our initiative to include more commentaries and rebuttals on key reviews is an integral part of this mission. Excellent examples of this mission exist including the debates found in the commentaries (Conner, Prestwich, \& Ayres, 2011; Gibbons, Wills, Kingsbury, \& Gerrarg, 2011; Perugini \& Richetin, 2011; Veling \& Aarts, 2011) and rejoinder (Wilhelm Hofmann, Friese, \& Wiers, 2011) to Hoffman, Friese and Weirs' (2008) original article on dual process models in health behaviour and Smith's (2011a) lead article and rebuttal (Smith, 2011b) on the use of Interpretive Phenomenological Analysis in health psychology and the diverse and varied commentaries from other health psychologists (Chamberlain, 2011; Kaptein, 2011; Shaw, 2011; Todorova, 2011).

The value of review articles in making sense of the important theoretical and research developments in health psychology is rising. In this article I have identified what I think makes a 
'good' review article and makes them an essential to researchers' and scholars' endeavours to make sense of the vast research literature in the field. I encourage readers to visit the articles I cite here (and others) bearing these features in mind in the hope that this inspires more academics, researchers, and students to conduct original, rigorous, evidence and theory-based reviews that advance thinking and future research in health psychology.

\section{References}

Annesi, J., Marti, C., \& Stice, E. (2010). A meta-analytic review of the Youth Fit For Life intervention for effects on body mass index in 5- to 12-year-old children. Health Psychology Review, 4, 621. doi: $10.1080 / 17437190903168561$

Borland, R. (2010). Habits and temporality: A commentary on Hall and Fong's Temporal SelfRegulation Theory. Health Psychology Review, 4, 66-69. doi: 10.1080/17437191003700816

Cameron, L. (2010). Temporal Self-Regulation Theory: Towards a more comprehensive understanding of health behavior. Health Psychology Review, 4, 70-74. doi: $10.1080 / 17437191003681537$

Chamberlain, K. (2011). Troubling methodology. Health Psychology Review, 5, 48-54. doi: 10.1080/17437199.2010.520113

Conner, M. P., Prestwich, A., \& Ayres, K. (2011). Using explicit affective attitudes to tap impulsive influences on health behavior: A commentary on Hoffman et al. (2009). Health Psychology Review, 5, 145-149. doi: 10.1080/17437199.2010.539969

DeFrank, J., \& Brewer, N. (2010). A model of the influence of false-positive mammography screening results on subsequent screening. Health Psychology Review, 4, 112-127. doi: 10.1080/17437199.2010.500482

DiMatteo, M. R., Haskard-Zolnierek, K. B., \& Martin, L. R. (2011). Improving patient adherence: A three-factor model to guide practice. Health Psychology Review, 6, 74-91. doi: 10.1080/17437199.2010.537592

Dodd, L., \& Forshaw, M. (2010). Assessing the efficacy of appearance-focused interventions to prevent skin cancer: A systematic review of the literature. Health Psychology Review, 4, 93111. doi: $10.1080 / 17437199.2010 .485393$

Floyd, A., \& Moyer, A. (2010). Group vs. individual exercise interventions for women with breast cancer: A meta-analysis. Health Psychology Review, 4, 22-41. doi: 10.1080/17437190903384291

Gibbons, F. X., Wills, T. A., Kingsbury, J. H., \& Gerrarg, M. (2011). Two ways of thinking about dual processing: A response to Hofmann, Friese and Wiers (2008). Health Psychology Review, 5, 158-161. doi: 10.1080/17437199.2010.541823

Gilliam, M. B., \& Schwebel, D. C. (2011). Physical activity in child and adolescent cancer survivors: A review. Health Psychology Review, Advance online publication. . doi: 10.1080/17437199.2011.603641

Hagger, M. S. (2009). Theoretical integration in health psychology: Unifying ideas and complimentary explanations. British Journal of Health Psychology, 14, 189-194. doi:

10.1348/135910708X397034

Hagger, M. S. (2010). Health Psychology Review: Advancing theory and research in health psychology and behavioural medicine. Health Psychology Review, 4, 1-5. doi: 10.1080/17437191003647306

Hall, P. A., \& Fong, G. T. (2010). Temporal Self-regulation Theory: Looking forward. Health Psychology Review, 4, 83-92. doi: 10.1080/17437199.2010.487180

Hofmann, W., Friese, M., \& Wiers, R. W. (2008). Impulsive versus reflective influences on health behavior: A theoretical framework and empirical review. Health Psychology Review, 2, 111137. doi: $10.1080 / 17437190802617668$ 
Hofmann, W., Friese, M., \& Wiers, R. W. (2011). Impulsive processes in the self-regulation of health behaviour: Theoretical and methodological considerations in response to commentaries. Health Psychology Review, 5, 162-171. doi: 10.1080/17437199.2011.565593

Kaptein, A. A. (2011). Pick up the pieces and go home - on the demise of health psychology. Health Psychology Review, 5, 39-47. doi: 10.1080/17437199.2010.520114

Lyons, A. C. (2011). Advancing and extending qualitative research in health psychology. Health Psychology Review, 5, 1 - 8. doi: 10.1080/17437199.2010.544638

Morton, K., Barling, J., Rhodes, R. E., Masse, L. C., Zumbo, B. D., \& Beauchamp, M. R. (2010). Extending transformational leadership theory to parenting and adolescent health behaviors: An integrative and theoretical review. Health Psychology Review, 4, 128-157. doi: $10.1080 / 17437191003717489$

Perez, G. K., \& Cruess, D. (2011). The impact of familism on physical and mental health among Hispanics in the United States. Health Psychology Review, Advance online publication. doi: 10.1080/17437199.2011.569936

Perugini, M., \& Richetin, J. (2011). Time matters. Health Psychology Review, 5, 154-157. doi: 10.1080/17437199.2010.529635

Sallis, J. F. (2010). Temporal self-regulation theory: A step forward in the evolution of health behavior models. Health Psychology Review, 4, 75-78. doi: 10.1080/17437191003681545

Shaw, R. L. (2011). The future's bright: celebrating its achievements and preparing for the challenges ahead in IPA research. Health Psychology Review, 5, 28-33. doi: 10.1080/17437199.2010.524808

Smith, J. A. (2011a). Evaluating the contribution of interpretative phenomenological analysis. Health Psychology Review, 5, 9-27. doi: 10.1080/17437199.2010.510659

Smith, J. A. (2011b). Evaluating the contribution of interpretative phenomenological analysis: A reply to the commentaries and further development of criteria. Health Psychology Review, 5, 5561. doi: 10.1080/17437199.2010.541743

Soundy, A., Smith, B., Dawes, H., Pall, H., Gimbrere, K., \& Ramsay, J. (2011). Patient's expression of hope and illness narratives in three neurological conditions: A meta-ethnography. Health Psychology Review, Advance online publication. doi: 10.1080/17437199.2011.568856

Stephens, C. (2011). Narrative analysis in health psychology research: Personal, dialogical and social stories of health. Health Psychology Review, 5, 62-78. doi: 10.1080/17437199.2010.543385

Sweeny, K., \& Cavanaugh, A. G. (2011). Waiting is the hardest part: A model of uncertainty navigation in the context of health news. Health Psychology Review, Advance online publication. doi: 10.1080/17437199.2010.520112

Todorova, I. (2011). Explorations with interpretative phenomenological analysis in different sociocultural contexts - comment on J. Smith: "Evaluating the contribution of interpretative phenomenological analysis". Health Psychology Review, 5, 34-38. doi:

10.1080/17437199.2010.520115

van 't Riet, J., \& Ruiter, R. A. C. (2011). Defensive reactions to health-promoting information: An overview and implications for future research. Health Psychology Review, Advance online publication. doi: 10.1080/17437199.2011.606782

Veling, H., \& Aarts, H. (2011). Stopping impulsive behavior by changing impulsive determinants of behavior. Health Psychology Review, 5, 150-153. doi: 10.1080/17437199.2010.539970

Webb, T. L., \& Sheeran, P. (2010). A viable, integrative framework for contemporary research in health psychology: Commentary on Hall and Fong's (2007) Temporal Self-Regulation Theory. Health Psychology Review, 4, 79-82. doi: 10.1080/17437191003717497 